on flat or gently inclined surfaces, such as summit terraces and platforms of SR and WSR. Further, data on metal content indicate that WSR and SR warrant further exploration because of the high concentrations of Co $(0.21 \%)$, $\sum$ REE (0.18\%) and Ni (0.76\%). Also, $\sum$ REE (range between 1094 and $2285 \mathrm{ppm}$ ) in the Fe-Mn crusts and nodules from WSR and SR are also promising as compared to the inner volcanic arc Fe-Mn crusts in the Andaman Sea ${ }^{5}$. Since there is high demand for REE, Co and other critical metals, the vast occurrences of $\mathrm{Fe}-\mathrm{Mn}$ crust within India's EEZ could be significant. Efforts are on to assess the economic viability of these $\mathrm{Fe}-\mathrm{Mn}$ crusts and nodules in terms of REE, Co, Li and other critical elements.

1. Hein, J. R., Conrad, T. A. and Dunham, R. E., Seamount characteristics and mine-site model applied to exploration- and mininglease-block selection for cobalt-rich ferromanganese crusts. Mar. Georesour. Geotechnol., 2009, 27, 160-176.

2. Muiños, S. B. et al., Deep-sea Fe-Mn crusts from the northeas Atlantic Ocean: composition andresource considerations. Mar. Georesour. Geotechnol., 2013, 31, 40-70.

3. Rajani, R. P., Banakar, V. K., Parthiban, G., Mudholkar, A. V. and Chodankar, A. R., Compositional variation and genesis of ferromanganese crusts of the Afanasiy-Nikitin Seamount, equatorial Indian Ocean. J. Earth Syst. Sci., 2005, 114, 51-61.

4. Banakar, V. K., Hein, J. R., Rajani, R. P. and Chodankar, A. R., Platinum group elements andgold in ferromanganese crusts of the Afanasiy-Nikitin Seamount, equatorial Indian Ocean: sources and fractionation. J. Earth Syst. Sci., 2007, 116, 3-13.

5. Surya Prakash, L. et al., Distribution of REEs and yttrium among major geochemical phases of marine Fe-Mn-oxides: comparative study between hydrogenous and hydrothermal deposits. Chem. Geol., 2012, 312-313, 127-137.

Received 23 October 2019; revised accepted 17 June 2020

\section{Ethnic food habits of the Sumi tribe, Nagaland, India}

\section{Lydia Yeptho*, T. Ajungla, Asangla Kichu and Maibam Romeo Singh}

Department of Botany, Nagaland University, Lumami 798627 , Zunheboto, India

The Sumis are one of the major tribes among the Nagas of North East India who are known for their brave and benevolent nature. They primarily inhabit the Zunheboto district of Nagaland, NE India, and are known for their unique culinary practices. Most of the

\footnotetext{
*For correspondence. (e-mail: yeptholydia@gmail.com)
}

raw materials used for the preparation of ethnic food products are natural resources indigenously available, as majority of the people live in villages surrounded by dense forest. The traditional method of preparation and mode of consumption vary according to the clan or village, and the food products are prepared at the household level. The diversity of ethnic food habits also differs within the various sub-tribes according to their custom, region and ethos. The art of indigenous food preparation, the products and their culinary value have been well documented.

Keywords: Culinary practice, ethnic food habits, natural resources, tribal people.

NAGALAND is the 16th state of the Indian Union, established on 1 December 1963 . It lies between $25^{\circ} 06^{\prime} \mathrm{N}$ and $27^{\circ} 04^{\prime} \mathrm{N}$ lat, $93^{\circ} 20^{\prime} \mathrm{E}$ and $95^{\circ} 15^{\prime} \mathrm{E}$ long, and covers an area of $16,579 \mathrm{~km}^{2}$ (ref. 1). It is a land of exuberant tribes marked by mountainous terrain and fields, and food is reflected as a part of its rich culture. The Sumi Nagas form one of the major tribes in Nagaland, and they predominately inhabit the Zunheboto district. Sumis are known for their bravery, nobility, generosity and their unique food habits which contribute to the rich cultural diversity of Nagaland. Majority of the Sumis are Christians, who practice jhum cultivation and live in villages. Each village consist of several clans and more than two dialects are spoken within the same tribe. The family organization is patriarchal and endogamy is the preferred mode of marriage. Even today, bridal prices are paid and it is considered a privilege by the other tribes in Nagaland to marry a Sumi man, because of his faithful and honourable nature.

Ethnic people cook traditional foods using raw materials that are locally available ${ }^{2-4}$. With the onset of human civilization, the dietary culture of many communities across the world has been shaped by the indigenous food products $^{5}$. Besides, ethnic foods also provide cure as medicine ${ }^{6,7}$. The knowledge on the use of edible plants, their processing and conservation for consumption and use as medicine is due to increasing and cumulative learning by the societies having a close connection with nature ${ }^{8}$. The traditional knowledge on ethnic food preparation among the Sumis is generally confined to the women folk or elders in the society, and such knowledge is passed thereon. The food products are prepared at the household level, for which the raw materials are gathered from the forests, fields or cultivated in kitchen gardens. The degree of diversity on the method of food preparation and products varies between villages and individuals. However, they have mastered the art of food processing and in turn these foods form an essential part of their culture and customs.

The present study was conducted in various areas, viz. Kohima, Dimapur and Zunheboto in Nagaland. Interactive questionnaire was used to document the traditional 
RESEARCH COMMUNICATIONS

Table 1. Ethnic plant products of the Sumi Nagas, India

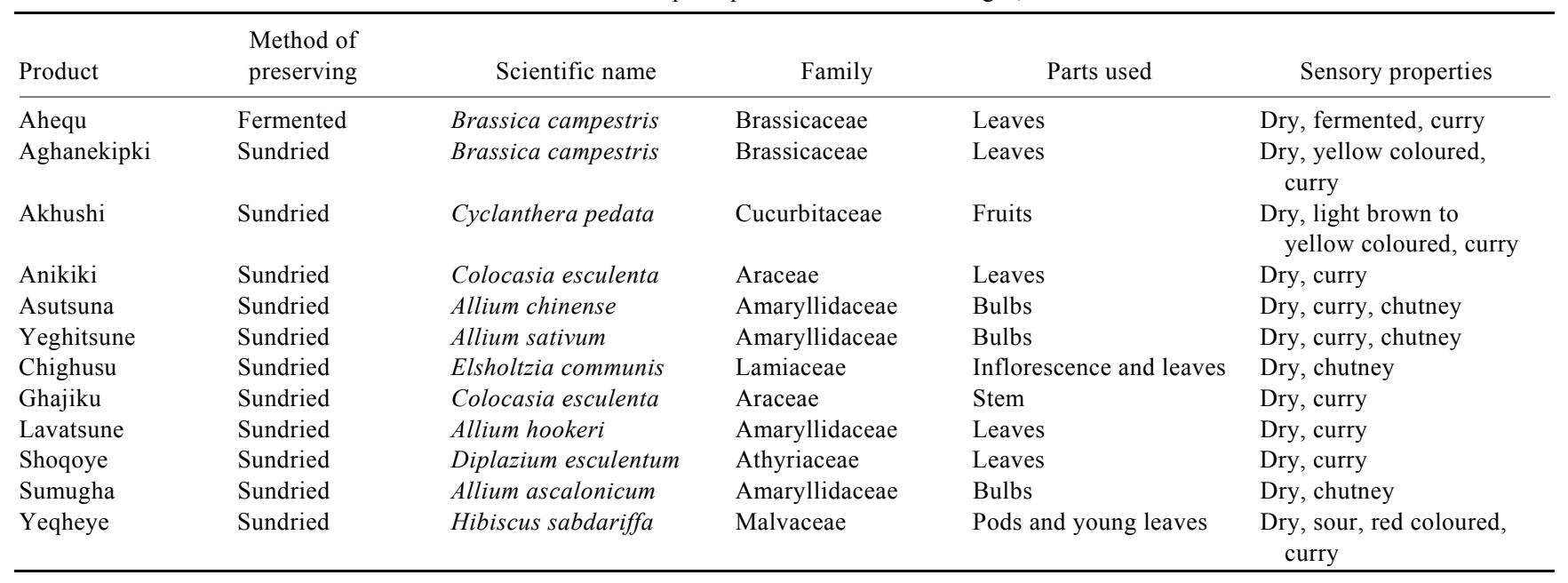
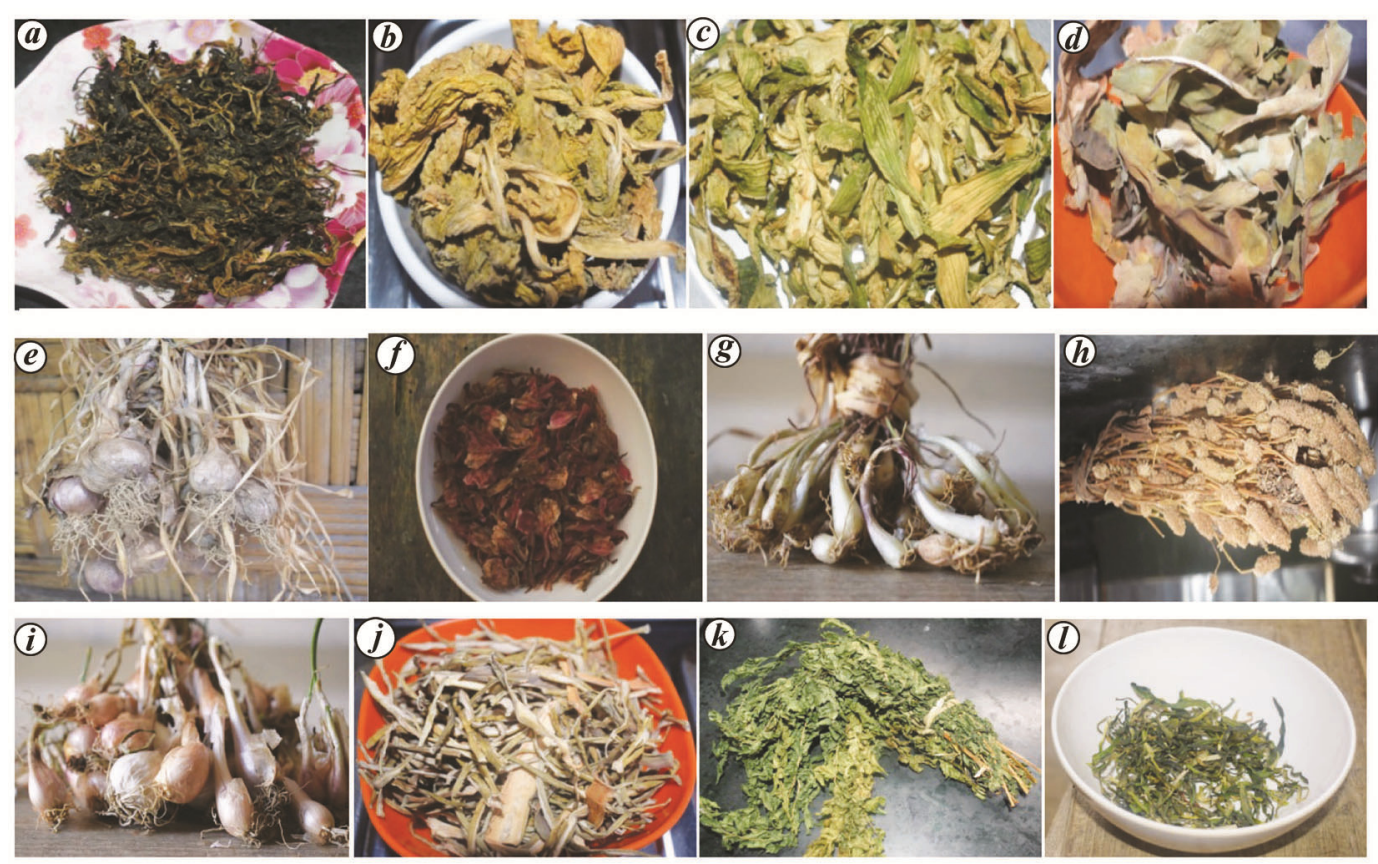

Figure 1. Ethnic plant products of the Sumi Nagas, India. $\boldsymbol{a}$, Ahequ; $\boldsymbol{b}$, Aghanekipki; $\boldsymbol{c}$, Akhushi; d, Anikiki; $\boldsymbol{e}$, Yeghitsune; $\boldsymbol{f}$, Yeqhiye; $\boldsymbol{g}$, Asutsune; $\boldsymbol{h}$, Chighusu; $\boldsymbol{i}$, Sumugha; $\boldsymbol{j}$, Ghajiku; $\boldsymbol{k}$, Shoqheye; $\boldsymbol{l}$, Lavatsune.

method of ethnic food preparation, the raw materials required for the same, culinary value of the food products, and the plant parts used. A common method employed by the Sumi tribe was chosen to represent their traditional practice and ethnic food habits. Table 1 represents the various ethnic plant products with their methods of preservation, scientific name, plant parts used and the sensory properties of the product. Figure 1 shows the various ethnic plant products used by the Sumi tribe of Nagaland, India. Similarly, Table 2 and Figure 2 represent the various ethnic cereal products; Table 3 and Figure 3 represent the various ethnic bean products used by the Sumi tribe of Nagaland, India.

Traditional method of preparation of vegetable products by the Sumi Nagas is as follows. (i) Sundried

Fresh and mature leaves/stems/flowers or bulbs collected.

$\downarrow$

Cleaned or washed.

$\downarrow$

Cut into small pieces/whole part kept intact.

$\downarrow$

Sundried (5-7 days).

$\downarrow$

Dried plant products. 
Table 2. Ethnic cereal products of the Sumi Nagas

\begin{tabular}{lllll}
\hline Product & \multicolumn{1}{c}{ Scientific name } & \multicolumn{1}{c}{ Family } & Parts used & \multicolumn{1}{c}{ Sensory properties } \\
\hline Aghuthi & Chenopodium album & Amaranthaceae & Seeds & Dry, side dish \\
Akuthu & Bambussa tulda & Poaceae & Shoots & Fermented, curry \\
Anau & Zea mays & Poaceae & Seeds & Dry, side dish \\
Ajiu & Z. mays & Poaceae & Seeds & Dry, side dish, beverage \\
\hline
\end{tabular}

\section{(ii) Fermented}

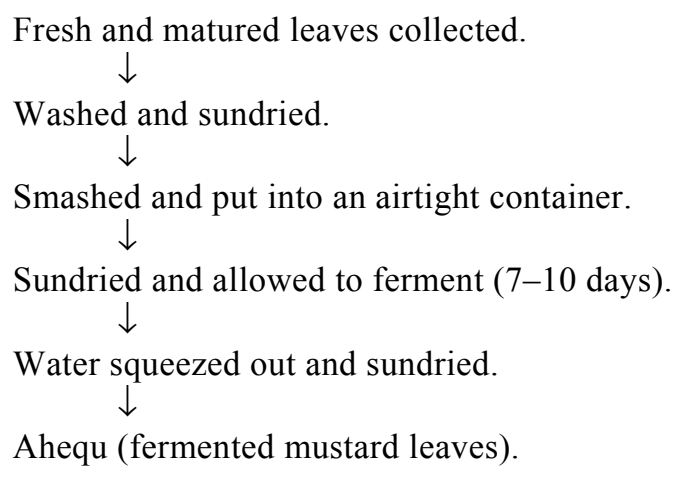

Culinary value: Majority of the sundried vegetable products are cooked with axone (fermented soybean) and smoked red meat as a curry preparation. They are also cooked with fish and added in vegetable curries. The sundried Allium bulbs are a popular ingredient for making chutney.

Traditional method of preparation of ethnic cereal products by the Sumi Nagas is as follows.

\section{(i) Sundried}

Collection of matured seeds.

$$
\downarrow
$$

The husk is removed or cleaned.

$$
\downarrow
$$

Sundried for 3-5 days.

$$
\downarrow
$$

Aghuthi/anau/ajiu

(ii) Fermented

Fresh and tender shoots collected.

$$
\downarrow
$$

Cut into pieces.

$$
\downarrow
$$

Filled into an airtight container with water.

$$
\downarrow
$$

Fermented for $2-4$ months.

$$
\downarrow
$$

Akuthu (fermented bamboo shoot).

Culinary value: The seeds of Chenopodium album are widely used among the poor as a substitute for rice, or sometimes mixed with rice and consumed as a leisure food similar to snacks. Fermented bamboo shoot is a common local delicacy prepared best with pork and fish. Fresh and tender bamboo shoots are either boiled or fried and consumed as a side dish.

Traditional method of preparation of ethnic bean products by the Sumi Nagas is as follows.

(i) Sundried

Mature and dried fruits collected. $\downarrow$

The outer coverings removed. $\downarrow$

Seeds sundried (2-4 days).

$\downarrow$

Ethnic cereal products.

(ii) Fermented

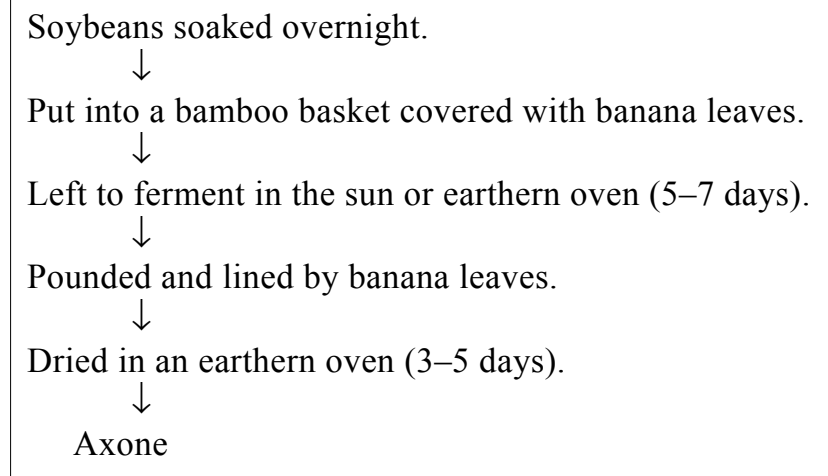

Culinary value: The dried bean products are used for curry preparation cooked with few pieces of fat. Axone is the most popular fermented food product associated with the Sumi Nagas. Axone with smoked pork is a delicacy that is popular among them. Egg boiled in axone and stirfried axone are some of the other delicacies. Dried axone which is prepared after boiling and fermenting by drying under the sun or in an earthen oven is used for making chutney or is deep fried.

Let us now consider the culinary value of other products.

Athumu (Figure $4 a$ and $b$ ) is obtained in powdered form by pounding the fruits of Rhus chinensis (Anacardiaceae) and is widely used by the Sumis. It is believed to have therapeutic properties and is eaten along with sugar 
RESEARCH COMMUNICATIONS

Table 3. Ethnic bean products of the Sumi Nagas

\begin{tabular}{lllll}
\hline Product & \multicolumn{1}{c}{ Scientific name } & Family & Parts used & Sensory properties \\
\hline Akixi & Vigna luteola & Fabaceae & Seeds & Dry, curry \\
Axalothi & Phaseolus vulgaris & Fabaceae & Seeds & Dry, curry \\
Kuthi khachi & P. vulgaris & Fabaceae & Seeds & Dry, curry \\
Kuthi kutsupu & Vigna mungo & Fabaceae & Seeds & Dry, curry \\
Kuthi woqhoghe & Vigna umbellate & Fabaceae & Seeds & Dry, curry \\
Axone & Glycine max & Fabaceae & Seeds & Fermented food product, dry, curry \\
\hline
\end{tabular}
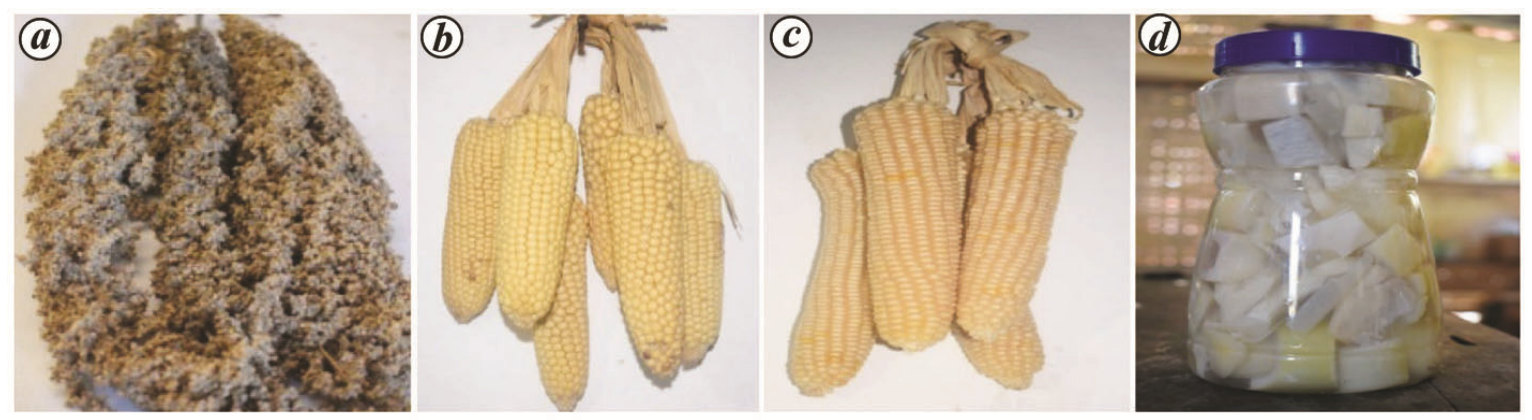

Figure 2. Ethnic cereal products of the Sumi Nagas. a, Aghuthi; b, Ajiu; $\boldsymbol{c}$, Anau; d, Akuthu.
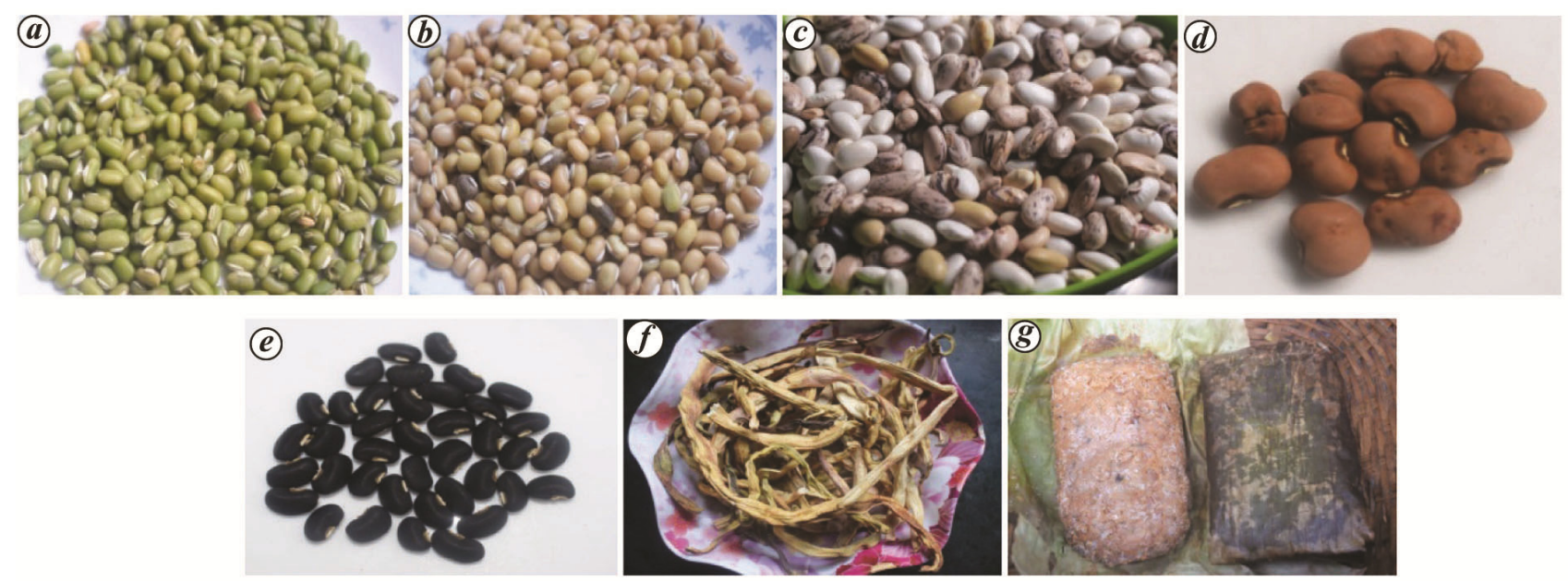

Figure 3. Ethnic bean products of the Sumi Nagas. $\boldsymbol{a}, \boldsymbol{b}$, Akixi; $\boldsymbol{c}$, Axalothi; $\boldsymbol{d}$, Kuthi woqhoghe; $\boldsymbol{e}$, Kuthi kutsupu; $\boldsymbol{f}$, Kuthi khachi; $\boldsymbol{g}$, Axone.

or honey during stomach disorders. It is also consumed during travel to prevent motion sickness or nausea. It is also added while preparing pork curry.

Angothi (Figure $4 c$ ) is the fruit of Zanthoxylum sp. (Rutaceae) and is the most popular spice used by the Sumi Nagas during preparation of meat curries. It is also used for preparing fried axone or fried meat pickles, and produces a pleasant smell. It is believed to increase the shelf-life of pickles.

Akini (Figure $4 d$ and $e$ ) is prepared by pounding the seeds of Perilla frutescens (Lamiaceae). Akini cooked with dried yam leaves is popular among the Sumis. Lazami's (sub-tribe of Sumi) also prepare akini with beans and pork fat as a side dish.
Kighithi (Figure $4 f$ ) is the fruit of Stixis suaveolens (Resedaceae), mostly used to make pickles. It is mixed with salt, chilly and mustard oil for pickle preparation. It is also taken in dried form garnished with salt and chilly. Kighithi is used to treat hypertension.

The Sumi Nagas maintain a close relationship with nature, and the art of utilizing the natural resources available to sustain their livelihood complements their ethnicity. However, it has been observed that the younger generation shows little or no interest on ethnic foods, their processing or dietary values. This may pose a threat to the rich knowledge that the people have preserved, which may succumb to the emerging culture of commercialization. Efforts must be made to improve the processing 

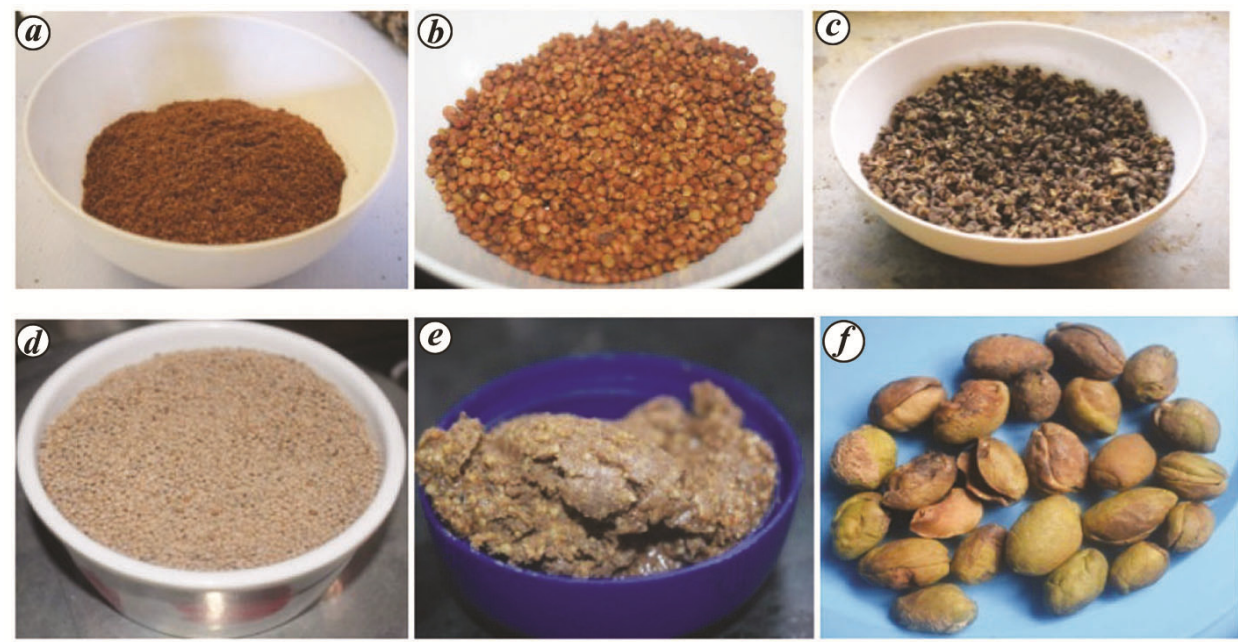

Figure 4. Ethnic food and fruit products of the Sumi Nagas. $\boldsymbol{a}, \boldsymbol{b}$, Athumu; $\boldsymbol{c}$, Angothi; $\boldsymbol{d}, \boldsymbol{e}$, Akini; $\boldsymbol{f}$, Kighithi.

methods, increase the shelf-life of food products, isolate productive strains, promote probiotic studies and contribute to food security in order to commercialize various food products in the global market. Hence, this study serves as a gateway to understand and preserve the food ethnicity of the Sumi tribe of Nagaland, which is threatened by ignorance or modernization, which directly or indirectly affects the identity and ethnicity of a culture in any society.

1. Deorani, S. C. and Sharma, G. D. (eds), Introduction. In Medicinal Plants of Nagaland, Bishen Singh Mahendra Pal Singh, Dehra Dun, 2007, pp. ixx-xxvii.

2. Tamang, J. P., Diversity of fermented foods. In Fermented Foods and Beverages of the World (eds Tamang, J. P. and Kailasapathy, K.), CRC Press, Taylor and Francis, Boca Raton, Florida, USA, 2010, pp. 41-84.

3. Tamang, J. P., Diversity of fermented beverages and alcoholic drinks. In Fermented Foods and Beverages of the World (eds Tamang, J. P. and Kailasapathy, K.), CRC Press, Taylor and Francis, Boca Raton, Florida, USA, 2010, pp. 85-125.

4. Tamang, J. P., Himalayan Fermented Foods: Microbiology, Nutrition and Ethnic Value, CRC Press, Taylor and Francis Group, New York, USA, 2010, pp. 6-9.
5. Tibor, D., Yeasts in specific types of foods. In Handbook of Food Spoilage Yeasts, CRC Press, Boca Raton, Florida, USA, 2007, 2nd edn, pp. 117-201.

6. Shin, D. H. and Jeong, D., Korean traditional fermented soybean products: Jang. J. Ethnic Foods, 2015, 2, 2-7.

7. Thapa, N. and Tamang, J. P., Functionality and the therapeutic values of fermented foods. In Health Benefits of Fermented Foods (ed. Tamang, J. P.), CRC Press, New York, USA, 2015, pp. 111-168.

8. Singh, A., Singh, R. K. and Sureja, A. K., Cultural significance and diversities of ethnic foods of Northeast India. Indian J. Tradit. Knowl., 2007, 6, 79-94.

ACKNOWLEDGEMENTS. We thank all the informants and elderly people, especially Kaholi D. Kiho and Kihoni for their valuable knowledge. We also thank Department of Biotechnology, Government of India for providing financial assistance and the research scholars in the Botany Department, Nagaland University, for help in the completion of this work.

Received 11 June 2020; accepted 1 July 2020

doi: $10.18520 /$ cs/v119/i4/708-712 